\title{
CONFLITOS TERRITORIAIS EM SÃO LUÍS DO MARANHÃO PELA IMPLANTAÇÃO DA USINA TERMELÉTRICA (UTE) PORTO DO ITAQUI ${ }^{1}$
}

\author{
FERNANDA CUNHA DE CARVALHO ${ }^{2}$ \\ Universidade Estadual do Maranhão \\ LÚCIA CONY FARIA CIDADE ${ }^{3}$ \\ Universidade de Brasília
}

\section{Introdução}

\begin{abstract}
Muitos dos conflitos sociais dos dias de hoje, do mesmo modo como ao longo da história, estão conotados por um sentido ecológico, sentido esse afiançado quando os pobres procuram manter sob seu controle os serviços e os recursos ambientais que necessitam para sua subsistência, ante a ameaça de que passem a ser propriedade do Estado ou propriedade privada capitalista. Eventualmente, os atores de tais conflitos são reticentes em se assumir como ambientalistas ou ecologistas, que de resto é terminologia recente na história social (MARTÍNEZ-ALIER, 2007, p. $347)$.
\end{abstract}

\footnotetext{
${ }^{1} \mathrm{O}$ presente artigo também está enquadrado como parte das pesquisas realizadas no âmbito do Grupo de Estudos Desenvolvimento, Modernidade e Meio Ambiente, da Universidade Federal do Maranhão (GEDMMA/ UFMA).

${ }^{2}$ Professora da Universidade Estadual do Maranhão e doutoranda na UNESP-Rio Claro. Contato: fer_nandacunha@yahoo.com.br.

${ }^{3}$ Professora da Universidade de Brasília. Contato: cony@unb.br.
} 
Buscando apoiar e promover o desenvolvimento econômico, o processo de gestão do território no Brasil tem se caracterizado pelo estabelecimento de redes de infraestrutura e grandes equipamentos, por meio de políticas públicas. Com uma vasta parte de seu território na Amazônia Legal e uma localização privilegiada para o escoamento de exportações de bens primários, o Maranhão tem sido objeto de inúmeros projetos. Em uma fase em que o modelo de desenvolvimento amplia a utilização de recursos naturais, projetos governamentais e empreendimentos privados têm ocasionado impactos negativos sobre o ambiente. Em São Luís, a capital do estado, o processo se acentua devido a efeitos negativos de investimentos recentes sobre comunidades locais, suscitando disputas e conflitos. Assim, o presente artigo objetiva analisar as relações existentes entre gestão do território - assumindo seu caráter de práticas de poder na disputa pelo território -, e conflitos ambientais, tomando por base o processo de implantação da Usina Termelétrica (UTE) Porto do Itaqui, em São Luís.

Situada em local privilegiado, São Luís apresenta características naturais e construídas favoráveis para a implantação de grandes projetos. Ligada ao Oceano Atlântico, uma das mais marcantes características naturais é a Baía de São Marcos, com profundidade natural mínima de 23 metros e, assim, adequada para navios de grande calado. Entre as principais características construídas pode-se destacar o Complexo Portuário do Itaqui, importante porto exportador de minério de ferro e de escoamento da produção da soja.

Nas décadas de 1970 e 1980, São Luís recebeu investimentos nacionais e internacionais como os da Vale - nome fantasia da Companhia Vale do Rio Doce (CVRD), adotado desde 2007 - e do Consórcio de Alumínio do Maranhão (Alumar), além da construção do Porto do Itaqui. Posteriormente, o aumento da demanda energética, em grande parte devido às exportações, suscitou a instalação da Usina Termelétrica Porto do Itaqui.

Além de efeitos sobre o quadro natural, a implantação da usina ocasionou impactos sociais particularmente negativos, afetando a acessibilidade e desarticulando a subsistência de moradores locais tradicionalmente estabelecidos nas cercanias do terreno da usina. Parte dessa população aceitou propostas de deslocamento e relocalização para áreas distantes. Outra parte, organizada, passou a agir: para manifestar-se e ser reconhecida, buscou comparecer às audiências públicas; na tentativa de recorrer a seus direitos de ocupação e acesso às terras, acionou o Ministério Público; com o apoio da mídia, realizou protestos. Pode-se considerar que tais manifestações, contrárias a ações de gestão do território e aos 
interesses dos promotores da implantação do projeto, configuram um conflito.

A crise ecológica e outros problemas relacionados à questão ambiental, somados ao modelo de gestão do território promovido por seu maior agente, o Estado, levam a uma configuração de tensões que ultrapassam a denotação de conflitos sociais (mesmo estando a eles agregados), somando às lutas valores ambientais.

De acordo com determinadas óticas, os conflitos sociais têm sido considerados processos negativos, como algo atípico. Outra perspectiva pode considerá-los choques ou embates que envolvem distintas racionalidades, associadas a diferentes agentes em defesa de seus interesses. Em vários casos, os conflitos ambientais têm sido relacionados a uma polarização ou confronto, que inclui, de um lado, a promessa do "progresso", embutida nos discursos da implantação de grandes projetos; de outro lado, seus impactos sobre a natureza e a sociedade.

Para Martínez-Alier, os conflitos ambientais estão cada vez mais presentes nas relações sociais da contemporaneidade, baseados em razões tão fortes quanto o acesso aos recursos naturais. Ao quadro geral podem-se acrescentar questões tão em voga como a destruição da camada de ozônio, o efeito estufa, a elevação do nível da água dos oceanos, o aumento das temperaturas, a poluição dos ambientes marítimos, a ameaça à biodiversidade e a escassez de recursos. Incluem-se, também, outras questões como o processo de defesa dos territórios, marcado por certo equilíbrio que seus ocupantes mantêm com o ambiente físico, bem como pelo desenvolvimento de ligações simbólicas (MARTÍNEZ-ALIER, 2007).

Com base na discussão apresentada, a pesquisa busca compreender em que medida as disputas pelo território contribuem para a emergência de conflitos ambientais no processo de implantação da Usina Termelétrica (UTE) Porto do Itaqui, em São Luís. Os procedimentos apoiaram-se em pesquisa bibliográfica, incluindo análises de programas e projetos governamentais. Acrescente-se o acompanhamento de processos participativos e observação direta; e a realização de entrevistas e conversas informais entre os diretamente atingidos e os pesquisadores que têm trabalhado com o tema. Nesse sentido a próxima seção apresenta aspectos conceituais sobre conflitos ambientais, na tentativa de compreender seu inter-relacionamento com processos mais amplos. A seção posterior apresenta um tratamento empírico da temática por meio de uma abordagem sobre conflitos advindos da implantação da Usina Termelétrica Porto do Itaqui, delineando seus principais elementos. 


\section{Gestão do Território e Conflitos Ambientais}

A noção de território volta-se para delineamentos materiais e supõe um enfoque político (CIDADE; VARGAS; JATOBÁ, 2008, p. 16). Sintetizando a visão de diferentes autores, a gestão do território pode ser considerada como uma prática de poder no espaço (BECKER, 1991, 1994; DA SILVA, 1993, p. 47; CORREAA, 1996, p. 23; SILVA, 1997, p. 54; SPOSITO, 1998). Complementar ao processo de planejamento, essa noção reflete não apenas os condicionantes de produção do sistema, mas também as prioridades de grupos hegemônicos. Em seu âmbito emergem conflitos envolvendo uma variedade de agentes sociais na defesa de seus interesses. Tais conflitos resultam de práticas que por vezes contrariam o planejamento na escala local, bem como ações de um Estado que, visto de maneira simplificada como representante da correlação de forças na sociedade, tende a favorecer os interesses da acumulação capitalista.

Nesse sentido, é possível que os sistemas que ignoram a existência de conflitos potenciais aumentem a possibilidade de sua ocorrência; e isso pode eventualmente resultar em problemas maiores. "O estabelecimento de sistemas hierárquicos rígidos pode aumentar a velocidade das decisões, mas, ao mesmo tempo, pode ignorar os interesses de alguns dos participantes do processo e colocar em risco o próprio sistema" (NASCIMENTO; BURSZTYN, 2010, p.67).

Considerando a variedade de processos e interesses envolvidos, a dinâmica que envolve a temática dos conflitos é bastante complexa. Para operacionalizar estudos e facilitar a inteligibilidade das dinâmicas envolvidas, alguns autores sugerem tópicos estruturantes. Platiau e outros consideram, de forma simplificada, quatro elementos centrais para informar a análise de conflitos de qualquer natureza: a) os atores; b) a natureza; c) os objetos; e d) as dinâmicas. (PLATIAU et al, 2005, p. 66.)

a) Atores ou agentes envolvidos

Os atores "podem ser definidos como indivíduos, grupos ou organizações de identidade própria, reconhecidos por outros, com capacidade de modificar seu ambiente de atuação" (NASCIMENTO, 2001, p. 95). Eles são movidos por interesses, valores e percepções próprios a cada um. Movimentam-se constantemente e modificam-se segundo a natureza do conflito. Também podem situar-se em diferentes escalas e são caracterizados por possuir diferentes racionalidades (diferença de valores, interesses e percepções), sendo estas as orientadoras de suas ações. 
Para efeito analítico, segundo Nascimento, ocupam cinco posições possíveis no interior de um conflito (2001, p. 96): (a) promoção: quando estão dispostos a se movimentar com todos os seus recursos para que haja um determinado desfecho; (b) apoio: quando têm uma posição favorável a determinadas iniciativas ou desfechos, mas não estão dispostos a se jogar com todas as forças no processo; (c) neutralidade: quando por alguma razão não têm ou não querem assumir posição favorável a qualquer dos lados em disputa; (d) oposição: quando se colocam contra determinadas iniciativas ou desfechos do conflito mas, não estão dispostos a utilizar todos os seus recursos; (e) veto: quando utilizam todos os seus recursos disponíveis para impedir que o conflito caminhe em um determinado sentido.

É importante destacar os estudos desenvolvidos por Bryant e Bailey (1997), nos quais os atores (agentes) ganham espaço e foco. Os autores apontam o exercício do poder, tanto no caso dos impactos gerados por um ator sobre outro, como pelo capital humano e financeiro, e também pelos meios discursivos. Entretanto, não se trata apenas do poder da classe dominante. Destaca-se, ainda, o poder que os agentes ditos mais fracos obtêm; o que se daria através do conhecimento local, da formação de redes e da elaboração de discursos que vão de encontro ao das classes hegemônicas, isto é, os contradiscursos. Nascimento e Bursztyn organizam a análise dos atores segundo sua posição, que pode ser interpretada como: (a) atores com posição contrária à ação; (b) atores com posição favorável à ação; (c) órgãos governamentais; e (d) mediadores. (NASCIMENTO; BURSZTYN, 2010, p.75-76).

Em outra perspectiva, o elemento campo refere-se ao espaço de movimentação dos agentes. Sua análise esclarece como as práticas de poder exercem influência sobre o ordenamento e gestão territorial. Assim, os variados agentes desenvolvem estratégias que são esboçadas no campo do conflito, seja o apego aos seus direitos e à legislação, como costumam fazer os "mais fracos", seja através da "chantagem locacional", como denomina Henri Acselrad (2010), as estratégias adotadas pelas empresas para sua instalação no local desejado.

b) Natureza dos conflitos

Os conflitos têm naturezas diferentes, predominando em épocas ou espaços diferentes. Envolvem racionalidades distintas que podem acarretar divergências e embates, particularmente ao envolver a ação social.

Por outro lado, de forma bem simplificada, a diferença básica entre conflitos sociais e conflitos ambientais estaria no fato de, no segundo caso, 
o meio natural se portar como parte integrante das disputas ${ }^{4}$. Em apoio a tal percepção, Henri Acselrad considera que os conflitos ambientais são:

Aqueles envolvendo grupos sociais com modos diferenciados de apropriação, uso e significação do território, tendo origem quando pelo menos um dos grupos tem a continuidade das formas sociais de apropriação do meio que desenvolvem, ameaçada por impactos indesejáveis, decorrentes do exercício das práticas de outros grupos (ACSELRAD, 2004, p. 26).

Segundo Zhouri e Laschefski (2010), há três modalidades de conflitos ambientais ${ }^{5}$ : (a) os distributivos, derivados das desigualdades sociais no acesso e na utilização dos recursos naturais; (b) os espaciais, engendrados pelos efeitos ou impactos ambientais que ultrapassam os limites entre os territórios de diversos agentes ou grupos sociais; (c) e os territoriais, relacionados à apropriação capitalista da base territorial de grupos sociais.

Os conflitos ambientais estão cada vez mais presentes em lugares em que a desigualdade se faz como consequência de dinâmicas sociais e econômicas atuantes sobre os territórios e seus recursos naturais, bem como por uma ausência ou fraca atuação de políticas estatais efetivas. Diferentes práticas e racionalidades na apropriação, uso e transformação da natureza podem ser geradoras de conflitos por defesa de territórios, identidades e recursos.

Os conflitos podem, assim, estar associados a diversas atividades e setores, envolvendo variados agentes sociais com distintas parcelas de poder e diferenciados interesses e racionalidades; e, também podem ser encontrados em diversas escalas. Tais fatos levam a uma necessária e inevitável análise sobre seu contexto histórico para que se tenha uma real compreensão sobre os mesmos.

\footnotetext{
${ }^{4}$ Os conflitos ambientais ou socioambientais são também sociais, mas nem todos os conflitos sociais são necessariamente ambientais.

${ }^{5}$ Tais modalidades não se excluem e podem até não servir como o "modelo ideal" nas análises sobre os conflitos, entretanto ajudam a compreender as suas derivações. Embora alguns conflitos possam se enquadrar em apenas uma modalidade, é comum a ocorrência de mais de uma no mesmo conflito.
} 
c) Objetos de disputa

Quanto ao objeto, este pode ser de natureza variável e também pode ser visto pelos agentes de formas diferenciadas. Isto significa dizer que a visão em torno do objeto depende da percepção e importância que lhes são atribuídas pelos agentes, tendo, portanto, maior relevância para uns do que para outros.

Geralmente os objetos são recursos ou bens escassos ou vistos como tais; podem ter natureza material ou simbólica, profana ou sagrada, pública ou privada, entre tantas outras. Nesse sentido, alguns objetos são materiais, outros políticos, por vezes assumem valores e ideologias, alguns até são demandados por uma ordem de crenças.

Com relação à problemática ambiental e considerando a existência do ambiente construído como a lógica vigente, os objetos acabam sendo derivados da relação sociedade-natureza, gerando discursos de preocupação e proteção e originando ou reorganizando conflitos ambientais. Isto significa dizer que as tensões e disputas demandantes da defesa da natureza são indissociáveis do funcionamento da sociedade.

d) Dinâmicas dos conflitos

Quanto à dinâmica, podem ocorrer conflitos em períodos mais ou menos intensos, de duração mais ou menos rápida e ainda ter lógicas distintas, com jogos de interesses que podem se tornar mais ou menos complexos. Três fases primordiais podem ser apontadas em um conflito: preparação, embate e conclusão. Por outro lado, "na impossibilidade de vitória ou de resolução, ele persiste, ingressando em uma espécie de fases crônicas, com manifestações precárias" (NASCIMENTO, 2001, p. 99). Alguns conflitos, mesmo que pareçam estar em fase de conclusão, podem retornar ao foco, caso algum ator envolvido se manifeste quanto a possível interesse ou impactos não contemplados adequadamente nas negociações.

Nesse sentido, discute-se a seguir como a gestão do território tem atuado no desenvolvimento de conflitos ambientais, destacando-se como as políticas de desenvolvimento que seguem uma lógica global são projetadas para um contexto nacional, e refletem-se intensamente nos espaços regionais e locais. Interferindo diretamente no lugar, essas políticas suscitam reações de grupos sociais e, quando há reações contrárias organizadas, podem constituir-se em conflitos ambientais. Considera-se, a seguir, a dinâmica territorial, os efeitos sobre as comunidades locais e os conflitos ambientais gerados pela implantação da UTE Porto do Itaqui. 


\section{Gestão do Território na UTE Porto do Itaqui: Um Conflito Latente}

\subsection{Contexto, ações privadas e políticas públicas de apoio ao empreendimento ${ }^{6}$}

O projeto da Usina Termelétrica Porto do Itaqui, da empresa paulista MPX Mineração e Energia Ltda., localiza-se em São Luís (Maranhão) no módulo $\mathrm{G}$ do Distrito Industrial, em um terreno de $50.000 \mathrm{~m}^{2}$, com uma distância aproximada de $5 \mathrm{~km}$ do Porto do Itaqui. Conta com apoio direto do Programa de Aceleração do Crescimento (PAC) do governo federal e apoio indireto do Plano Nacional de Energia (PNE) e do Plano Decenal de Expansão de Energia 2007/2016 (PDEE), considerando os planejamentos traçados para a região.

$\mathrm{O}$ valor do empreendimento foi estimado em $\mathrm{R} \$ 1,5$ bilhão, com financiamento fornecido pelo Banco Nacional de Desenvolvimento Econômico e Social (BNDES), Bradesco e Votorantim, Banco do Nordeste do Brasil - Fundo Constitucional de Financiamento do Nordeste (BNBFNE). A MPX Itaqui tem parceria, no contrato de Engenharia, Construção e Montagem, com a Mabe Construção e Administração de Projetos Ltda. uma sociedade entre as empresas Tecnimont e Efacec. As turbinas da planta foram supridas pela Siemens e as caldeiras, pela Doosan Babcock.

$\mathrm{O}$ estabelecimento da usina gerou impactos sobre o quadro natural e, particularmente, sobre a população de duas áreas, limitando o acesso a seus assentamentos e dificultando atividades tradicionais de agricultura e pesca. Enquanto a população residente em Vila Madureira aceitou ser relocalizada, grupos de Camboa dos Frades, contrários a deslocamentos, organizaram-se, buscaram apoios e efetivaram protestos.

\footnotetext{
${ }^{6}$ As informações deste item estão baseadas no Estudo de Impacto Ambiental feito para a implantação da Usina Termelétrica Porto do Itaqui. Ver: Diferencial Energia Empreendimentos e Participação Ltda, 2008.
} 


\subsection{Atores ou agentes envolvidos no conflito da comunidade Camboa dos Frades}

a) Atores com posição contrária à ação

A comunidade Camboa dos Frades é um agente central para a compreensão do conflito ${ }^{7}$. Assume posição de veto, uma vez que tenta impedir que o conflito caminhe no sentido de que a comunidade perca o que reconhece como seus direitos (sobretudo o de propriedade do território).

A participação de movimentos sociais, todos caracterizados pela oposição, também tem papel de destaque. O Reage São Luís é um deles e pode ser classificado como "um projeto sociopolítico antagônico às elites políticas dirigentes no Maranhão. O movimento argumenta que o estado necessita de um novo modelo de desenvolvimento" (LIMA, 2009, p. 226). O Reage São Luís também é um movimento social que ganha destaque ao atuar junto às comunidades contestatórias no momento das audiências públicas voltadas à viabilização de instalação do projeto. Para tal passou a orientar a comunidade sobre uma diversidade de aspectos formais do processo de implantação de indústrias, sobretudo através do fornecimento e esclarecimento de informações técnicas.

Outro movimento que atuou no processo, através do acompanhamento dos fatos e no fortalecimento da resistência ao não deslocamento compulsório da comunidade, foi o Fórum Carajás. Este se reconhece como uma teia de entidades do Maranhão, Pará e Tocantins que acompanha as políticas de projetos para a Região do Projeto Grande Carajás, promovendo atividades de sensibilização da opinião pública, formação de lideranças, realizando estudos no sentido do fortalecimento do movimento popular para uma intervenção mais qualificada nas políticas públicas e consequentemente maior democratização na distribuição dos recursos.

b) Atores com posição favorável à ação

A MPX é uma empresa do grupo EBX que está se posicionando no setor elétrico brasileiro para atender ao mercado regulador e ao mercado livre. Iniciou suas atividades no setor elétrico a partir do desenvolvimento de uma termelétrica no estado do Ceará, em 2001.

\footnotetext{
${ }^{7} \mathrm{O}$ processo envolvendo a comunidade será melhor explicado nos itens 3.4 (objetos de disputa) e 3.5 (dinâmicas dos conflitos de Camboa dos Frades).
} 
No contexto do conflito ludovicense, a empresa se posiciona como agente de promoção (trabalhando para que o conflito tenha um desfecho). Poderia ser vista como o contraponto da comunidade apresentada, oferecendo uma lógica, que mesmo não sendo exatamente binária, demonstra o processo de disputa comunidade versus empresa.

c) Órgãos governamentais

O Estado (poder público) é um forte agente de apoio (assumindo uma posição favorável à implantação do projeto termelétrico) e possui vertentes diferentes, porém, interligadas a partir da escala que se analisa. No âmbito municipal, ele possibilitou a conversão legislativa de zona rural para zona industrial; no âmbito estadual forneceu incentivos para a implantação do projeto; e no âmbito federal dota a empresa de recursos através do Programa de Aceleração do Crescimento do governo, e é responsável pela compra da energia a ser gerada.

O IBAMA, enquanto órgão competente para realizar o licenciamento ambiental do projeto, permitiu sua implantação autorizando o início das obras de terraplanagem, por tal, também pode ser visto como um ator que assume posição de apoio. Entretanto, para que o início das obras seja liberado ele impôs 102 condicionantes que devem ser cumpridas para que seu funcionamento se realize. Só resta saber se depois da instalação física concluída, o órgão realmente exigirá o cumprimento de tais pontos.

O Ministério Público também obteve importante atuação, situando-se enquanto um agente de oposição, indo contra determinadas iniciativas do projeto, mas das formas que lhes são possíveis. Foi através dele que a empresa MPX teve que assinar um Termo de Ajustamento de Conduta (TAC), por romper a passagem que a população de Camboa dos Frades tinha até a BR-135, assim, se responsabilizando por construir uma nova via para a comunidade.

d) Mediadores

As Universidades Estadual e Federal, na figura de alguns de seus funcionários e estudantes, podem ser vistas por duas vertentes. A primeira estaria na figura de alguns professores de tais instituições que foram contratados para fazer o Estudo de Impacto Ambiental e o Relatório de Impacto Ambiental (EIA/RIMA) do projeto a ser executado, compondo parte da equipe da ERM Brasil Ltda, sendo agentes de promoção. A segunda vertente estaria na figura do grupo de estudos denominado GEDMMA (Grupo de Estudo: Desenvolvimento, Modernidade e Meio Ambiente), da Universidade Federal do Maranhão, que busca atuar 
fornecendo à comunidade análises pautadas em conhecimentos científicos e nos estudos que efetuam, por vários olhares, sobre a realidade que se passa no povoado, sendo caracterizado no interior do conflito como agentes de neutralidade, embora, por vezes, assumam situações de oposição, como resultados indicativos de seus estudos.

\subsection{Natureza dos conflitos: UTE Porto do Itaqui $X$ comunidade Camboa dos Frades}

A natureza do conflito é apresentada como ambiental ou socioambiental, considerando que o cerne do conflito gira em torno de interações ecológicas (LITTLE, 2004, p. 1). Isto significa dizer que a comunidade Camboa dos Frades, caracterizada por possuir base agroextrativista, mantém uma relação de equilíbrio com o ambiente. Logicamente há uma ressalva de que tal relação se dá devido aos recursos naturais servirem para sua subsistência e comercialização, mas o fator principal da abordagem consiste no fato de que a população consegue aliar seu modo de vida à preservação do ambiente natural. Fator que não ocorre com o processo de implantação da usina termelétrica em questão. A implantação da termelétrica altera o habitus (BOURDIEU, 1983) existente no território.

$\mathrm{O}$ referido projeto de energia elétrica foi projetado para ter capacidade de produção de $360 \mathrm{MW}$ na sua primeira fase, tal capacidade será duplicada em uma fase subsequente. O projeto possui uma vida útil esperada de 25 a 30 anos. Já foram comercializados 315 MW de energia no leilão A5, correspondente à energia nova, promovido pela Agência Nacional de Energia Elétrica (ANEEL) em outubro de 2007, para contratos de fornecimento de 15 anos, que deveria ter início em janeiro de 2012.

O combustível utilizado no processo é o carvão mineral vindo da Colômbia ${ }^{8}$ (dos Departamentos de La Guajira e Cesar) que, segundo a empresa, tem uma qualidade superior, pelo baixo teor de enxofre e cinzas.

\footnotetext{
${ }^{8}$ A empresa é também detentora das áreas que abastecerão a UTE de carvão e afirma que o objetivo das concessões minerais na Colômbia é "consolidar sua estratégia de sistemas integrados de energia, aliando a gestão de recursos naturais colombianos ao suprimento de projetos termelétricos no Brasil e no Chile. Além disso, a empresa pretende atender a grande e crescente demanda do mercado internacional". Informação retirada do site: http://www.mpx.com.br/pt/nossos-negocios/recursos-naturais/Paginas/minas-dacolombia.aspx. Acessado em 08 de outubro de 2011.
} 
O Porto do Itaqui possibilita o recebimento do carvão que, em seguida, será transportado seguindo uma faixa de servidão junto à BR-135, até chegar à área de estocagem (terreno que terá capacidade de suporte de material para 30 dias de operação). Tem uma previsão de operação anual que varia de 4 a 6 meses, atendendo demandas do sistema elétrico nacional.

\subsection{Objetos de disputa}

É exatamente nesse contexto que se apresenta como objeto em estudo o território, caracterizando o conflito como relacionado à apropriação capitalista da base territorial de grupos sociais (ZHOURI \& LASCHEFSKI, 2010). Situado na periferia da cidade de São Luís, o projeto da Usina Termelétrica Porto do Itaqui localiza-se em uma área que era caracterizada, pouco tempo antes de sua implantação, como de uso predominantemente rural. Tal fato apresenta indicativos de mudança quando o governo, no ano de 2004, anuncia ${ }_{9}$ o projeto de um polo siderúrgico que deveria ser instalado em São Luís 9 .

Mesmo após ter conseguido mudar a destinação de 1.063,6088 hectares de área rural para área industrial, o governo do estado encontrou diversos e significativos entraves para a efetivação do polo. Dessa forma, após embates com diferentes agentes em torno de interesses de preservação ambiental no município, a siderúrgica transferiu-se para o Rio de Janeiro. Posteriormente, houve na mesma área a implantação de uma usina termelétrica, atingindo diretamente duas comunidades: a comunidade Vila Madureira, com 95 famílias, e a comunidade Camboa dos Frades, constituída por 40 famílias.

Entrevistas realizadas com moradores da comunidade indicam que há indícios de ocupações ancestrais em ambas as comunidades. Na Vila Madureira, indicações da antiguidade aparecem, sobretudo, através de registros orais, em que se têm a afirmação de habitantes com mais de 50 anos de idade que dizem ter nascido na comunidade e que alegam que seus pais já residiam no local há mais tempo. Em Camboa dos Frades, segundo

${ }^{9} \mathrm{O}$ polo seria composto por três usinas siderúrgicas com capacidade de produção de 7,5 milhões de toneladas anuais de placas de aço, voltadas à exportação, totalizando 22,5 milhões de toneladas/ano, e duas gusarias, em uma área de $2.471,71$ hectares, próxima ao Porto do Itaqui (ZAGALLO, 2004). Essa área compõe um mosaico de 12 comunidades rurais, ribeirinhas de marisqueiros e pescadores, bem como de quilombolas. 
Pereira (2008), famílias de pescadores oriundos do interior do estado foram atraídas, no ano de 1920, devido à sua localização e à rica biodiversidade do ambiente estuarino preservado, propício à pesca, à criação de animais e extração vegetal.

Alguns moradores das referidas comunidades declararam que não possuem empregos fixos e os empregados frequentemente têm funções de baixa renda, trabalhando como domésticas, eletricistas, pintores. Geralmente fazem os chamados 'bicos' nos serviços de capina e na construção civil (como pedreiro, encarregado de obras e servente). Há ainda uma parcela de aposentados.

Nesse contexto, suas subsistências se davam, ou eram fortalecidas, por criač̃os de animais de pequeno porte e por plantios de variadas culturas $^{10}$, todos cultivados em seus quintais. Dentro do sistema de aproveitamento dos recursos naturais, geralmente as mulheres dedicam-se à quebra do coco babaçu, extraindo o óleo para comercializar, e os homens à pesca, voltada ao consumo do que for necessário para manutenção de suas famílias e venda do excedente.

Para que fosse possível a implantação estrutural da usina termelétrica, a comunidade Vila Madureira teve que ser deslocada (considerando que as instalações físicas do projeto ocupam exatamente a área que abrigava a comunidade). Assim, houve um 'acordo' que culminou em um processo de deslocamento da comunidade para uma área localizada no município de Paço do Lumiar, que fica a $40 \mathrm{~km}$ de distância da área de moradia anterior. A comunidade, que era denominada Vila Madureira, passou então a ser conhecida como residencial Nova Canaã. Foram construídas 95 casas $^{11}$, em uma área de 25 mil metros quadrados. A comunidade também recebeu um polo agrícola, localizado no bairro da Pindoba, que possui 56 hectares e fica distante $5,5 \mathrm{~km}$ do residencial.

A comunidade Camboa dos Frades não foi inicialmente percebida pelos empreendedores como uma área diretamente atingida, mesmo contando a sua grande proximidade com o projeto. Entretanto, o início das

\footnotetext{
10 Entre as culturas com destaque estão: arroz, milho, macaxeira, feijão, banana, caju, coco, limão, maracujá, murici, buriti, juçara e abóbora.

${ }^{11}$ Os residentes da Nova Canaã foram beneficiados com fogão, geladeira, liquidificador, aparelho de televisão e computador, em cada casa. Em pesquisa anterior (CARVALHO, 2011) foi constatado que as casas só poderiam ser comercializadas três anos após o deslocamento, mas já havia registro de 1 (uma) que estava disposta à venda, mesmo antes desse prazo acabar.
} 
obras de terraplanagem, com a Vila Madureira já remanejada, demonstrou que a comunidade estava tendo seu único acesso à terra firme destruído, e que ela ficaria sem possibilidades de se deslocar - o que a isolaria entre o empreendimento e a Baía de São Marcos.

É importante considerar que o campo de atuação do referido projeto (durante o período de implantação) não estava restrito somente à comunidade Camboa dos Frades, embora o campo de conflito sim. O território antes conhecido como Vila Madureira não pode ser configurado como área em disputa, por já ter sido apropriado pelo projeto e por não ter apresentado processo de resistência quando se falou sobre seu remanejamento.

\subsection{Dinâmicas dos conflitos de Camboa dos Frades}

A restrição da acessibilidade dos moradores de Camboa dos Frades dos locais de moradia e subsistência a outras áreas configura uma forte característica que fez com que as reclamações sobre a instalação do projeto - não atendidas - se tornassem um processo de resistência. Havia, sobretudo, o medo dos habitantes do povoado de ter que sair de suas terras à força e sem nenhuma indenização, já que ficariam sem opções viáveis de moradia caso um novo acesso não fosse construído.

A população resistiu e passou a protestar buscando apoio na mídia, nos grupos de cunho socioambientalista (como o Fórum Carajás), na Defensoria Pública Estadual, na academia e no Ministério Público. Depois de muitas reivindicações, a empresa foi obrigada a assinar um Termo de Ajuste de Conduta (TAC) e, consequentemente, construir uma nova estrada para a comunidade.

Entretanto, considerando que se mantém no local mas com receio permanente de ser retirada a qualquer momento, a comunidade ainda tem lutado por meio de demandas levadas ao poder público. A argumentação se baseia no fato de ser uma comunidade antiga, possuidora de um modo de vida especificamente ligado ao ambiente natural, bem como de possuir registros importantes para a história do Maranhão e do Brasil ${ }^{12}$.

${ }^{12}$ Como se refere o processo ${ }^{\circ}$ 1494.000161/2008-17 do IPHAN (Instituto de Patrimônio Histórico e Artístico Nacional) relativo ao Programa de Prospecção Arqueológica na área de Implantação da Usina Termoelétrica Porto de Itaqui - São Luís - MA. Tal documento indica insuficiência e irregularidades no EIA-RIMA no que se refere à prospecção 
Outros problemas trazem efeitos negativos, tais como o assoreamento dos igarapés utilizados para a pesca e a possível e consequente diminuição do pescado, já que o desmatamento e o aterramento para instalação das obras estariam causando a descida de areia, barro e lama. Dadas as circunstâncias, o conjunto de ações da comunidade através de seu processo de resistência constituiu o que pode ser considerado como um conflito ambiental. Assim, o Quadro 1 apresenta uma síntese do conflito pesquisado, destacando seus principais elementos.

\begin{tabular}{|c|l|}
\hline \multirow{2}{*}{ Atores } & $\begin{array}{l}\text { lomunidade Camboa dos Frades, Movimentos Sociais, } \\
\text { Empresa MPX, Estado, IBAMA, Ministério Público } \\
\text { Universidades Estadual e Federal }\end{array}$ \\
\hline Natureza & Ambiental/ Socioambiental \\
\hline Objeto de disputa & Território: comunidade x indústria \\
\hline Dinâmica do conflito & $\begin{array}{l}\text { A instalação da Usina Termelétrica Porto do Itaqui, da } \\
\text { empresa MPX, levou a comunidade Camboa dos Frades a } \\
\text { ficar isolada atrás da construção do projeto e a reagir. } \\
\text { Após pressões da comunidade e apoiadores, o governo } \\
\text { estabeleceu medidas de mitigação por parte da empresa. }\end{array}$ \\
\hline
\end{tabular}

Quadro 1: Elementos do Conflito de Camboa dos Frades.

Fonte: CARVALHO, 2011 (com modificações).

A pesquisa evidencia que, mesmo tendo tido caminhos e resultados diferentes quanto às ameaças a seu modo de vida, as comunidades têm se manifestado claramente no processo de luta pelos seus direitos. Além da questão da sobrevivência econômica, processos de apego ao lugar, organização comunitária e coesão social podem configurar como estratégias adotadas no processo de luta ou não por permanência no território. No caso de Vila Madureira, na medida em que a permanência em área a ser ocupada pelo empreendimento industrial estaria sempre em risco, prevaleceu a luta por uma transferência pactuada para outra área, embora envolvesse perdas. No caso de Camboa dos Frades, a viabilidade da

arqueológica, desprezando os indicativos arqueológicos ali existentes, datados do século XVII. 
permanência parece ter atuado no sentido da construção de uma estratégia de confronto.

\section{Considerações Finais}

O texto tratou da diversidade de relações envolvidas no processo de conexão entre gestão do território, traduzido pelas relações de poder e conflitos ambientais, com foco na implantação da Usina Termelétrica (UTE) Porto do Itaqui, em São Luís. Buscou compreender em que medida o Estado tem um papel de domínio no processo ao atuar em articulação com agentes hegemônicos. Apresentou as diferentes formas pelas quais as comunidades de Vila Madureira, atual Residencial Nova Canaã, e de Camboa dos Frades adotaram ao reagir ao novo empreendimento promovido pela empresa MPX com o apoio do Estado.

A antiga comunidade Vila Madureira, atual Residencial Nova Canaã, era constituída por moradores que, apesar de apresentarem pontos que demonstravam sua ligação com o local de moradia (manifestados, sobretudo, por suas formas de manutenção através da coleta de recursos da natureza), alegaram que habitavam em uma área bastante poluída, bem como se sentiam constantemente inseguros por residirem em um território detentor de muitos interesses manifestados pela instalação industrial. Assim, a comunidade vislumbrou a possibilidade de, através da sua luta para não sair sem indenização, se relocalizar em nova área onde obteria títulos de terra. Além disso, a área contaria com estrutura agrícola voltada à continuidade da manutenção da comunidade através dos recursos locais. A comunidade - representada pelo presidente da associação de moradores decidiu aceitar a proposta da empresa MPX e se deslocar para outra área, através de um acordo sem resistências.

Já a comunidade Camboa dos Frades decidiu lutar para permanecer em seu território. A empresa MPX não deixou claro que queria se apropriar da área da comunidade, entretanto, as análises sobre o processo levam a uma compreensão de estratégias utilizadas para que a comunidade se retirasse do seu lugar por vontade própria. Um importante fator que diferencia esta comunidade da comunidade que se transferiu para Nova Canaã é o apego manifestado pelo território. Isso se revela em alegações da proximidade com o mar, dos plantios, da segurança que as crianças têm em brincar nas áreas públicas, dentre outros fatores. E demonstrada uma maior coesão social entre as famílias, embora, também de forma estratégica 
(acredita-se), tenha se tentado enfraquecer o poder da organização comunitária lá existente.

As análises indicam a permanência de um modelo de desenvolvimento articulado em escala global ou nacional com impactos que atingem a escala local. Enquanto grandes projetos acabam não garantindo melhorias na qualidade de vida da população, podem ocasionar uma desestruturação territorial e um aumento das desigualdades. Em um quadro de distintos interesses, além da formação de discursos há também a elaboração de contradiscursos, caracterizando processos de resistência e configurando conflitos. Quando têm suas centralidades em questões ambientais são conhecidos como conflitos ambientais.

A pesquisa revela que a área agora ocupada pela construção da UTE tornou-se um espaço vazio de sentido para os antigos habitantes das comunidades, bem como para os que ainda resistem em ficar atrás das instalações físicas da obra. As formas e as outras funcionalidades outrora atribuídas se sobrepuseram à apropriação do lugar da comunidade enquanto espaço do cotidiano, do modo de vida, do relacionamento com o outro.

O espaço em estudo tem revelado a ocupação a partir do processo de divisão social e técnica do trabalho em nível mundial, que, ao criar uma hierarquia espacial, reproduz morfologia que se manifesta na desigualdade. Manter-se unidos em torno do reconhecimento de que são comunidades tradicionais e extrativistas suscita símbolos ligados ao fato de estabelecerem uma vida cotidiana em "equilíbrio" com o ambiente natural, e estimula o desenvolvimento de lideranças, motivando a manutenção de sua dinâmica interna. O processo de implantação da UTE Porto do Itaqui demonstra que esse fato atingiu comunidades locais em sua relação com o território e, particularmente, com o ambiente, suscitando reações sociais, demarcando o conflito ambiental local.

Considera-se o conflito como latente pois, apesar das tentativas de manifestações exteriores, ele acaba sendo ocultado pelos jogos de poder e estratégias, como tentativas de ganho de território, não declaradas pela UTE. Entretanto é importante ressaltar que a atual abordagem do conflito pode tomar outras configurações, posto que é um processo ainda em curso.

As forças de resistência do lugar, que veem nas suas possibilidades de comunicação e organização, reforçadas grandemente por uma coesão social, maneiras de afirmarem suas lutas e se fazerem visíveis, abrem possibilidades de serem, também, responsáveis pela construção do território. 
CONFLITOS TERRITORIAIS EM SÃO LUÍS DO MARANHÃO PELA IMPLANTAÇÃO DA USINA TERMELÉTRICA (UTE) PORTO DO ITAQUI

Resumo: No apoio a atividades econômicas, políticas de gestão do território envolvem uma diversidade de interesses. No Brasil, ao contribuir para ampliar vantagens competitivas em áreas estratégicas, ações governamentais têm também ocasionado alterações de modos de vida locais. Beirando a Amazônia e se estendendo sobre o cerrado, o estado do Maranhão é palco da coexistência entre sistemas tradicionais e frentes de modernidade. A capital, São Luís, situa-se em relativa proximidade a importantes fontes de matérias primas minerais e a áreas produtoras de grãos. Em decorrência de características naturais particularmente favoráveis na baía, o porto conta com grandes equipamentos de apoio logístico a exportações. Ao impactar negativamente o quadro ambiental e ao modificar ou restringir o acesso a áreas ocupadas por populações tradicionais, novos empreendimentos têm ocasionado inúmeras tensões. Assim, o texto analisa a implantação da Usina Termelétrica Porto do Itaqui em São Luís e a forma como esse processo atingiu comunidades locais em sua relação com o território e com o meio natural. Adota a pesquisa bibliográfica e complementa-se com observação direta e entrevistas informais com agentes representativos. Depreende que o processo suscitou reações sociais, configurando-se, assim, uma situação de conflito ambiental. Os desdobramentos se apresentaram de forma diferenciada segundo o tipo de ação proposta para distintas comunidades envolvidas.

Palavras-chave: industrialização, UTE Porto do Itaqui, conflitos socioambientais.

TERRITORIAL CONFLICTS IN SÃO LUÍS (MARANHÃO) WITH THE CONSTRUCTION OF PORTO DO ITAQUI THERMOELECTRIC POWER STATION

Abstract: In support for economical activities, territorial management policies involve a wide diversity of interests. In Brazil, while contributing to broaden competitive advantages in strategic areas, governmental actions have entailed alterations in local life-styles. Adjacent to the Amazon rainforest and unfolding through the savannah, the state of Maranhão represents a scenario for the coexistence of traditional systems and 
modernity fronts. The capital, São Luís, stands near important mineral sources and grain production areas. Due to natural characteristics of the bay, the port offers large scale logistic equipment to convey exports. Negatively impacting the environment and altering or restricting access to areas occupied by traditional populations, new projects have produced a number of tensions. Thus, this text analyses the implementation of Porto do Itaqui thermoelectric power plant in São Luís as well as the ways in which this process reached local communities in their relation with the territory and natural environment. Analysis dwells on bibliographic research as well as on direct observations and informal interviews with representative agents. It shows that the process has raised social reactions, thus constituting an environmental conflict. The developments appeared in different ways according to type of action proposed for different communities involved.

Keywords: industrialization, Porto do Itaqui thermoelectric power plant, socioenvironmental conflicts.

\section{Bibliografia}

ACSELRAD, H. (org.). (2004) Conflitos ambientais no Brasil. Rio de Janeiro: Relume Dumará: Fundação Heinrich Böll.

(2010) Ambientalização das lutas sociais - o caso do movimento por justiça ambiental. Estudos Avançados [online]. vol.24, n.68, p. 103-119. Disponível em: <http://dx.doi.org/10.1590/S010340142010000100010>. Acessado em: 3 set. 2011.

BECKER, B. K. (1994) Amazônia. $3^{\circ}$ ed. São Paulo: Editora Ática.

. (1991) Modernidade e gestão do território no Brasil: da integração nacional à integração competitiva. Espaço e Debate, n. 32, p. 47-56.

BOURDIEU, P. (1983) Questões de sociologia. Rio de Janeiro: Marco Zero.

BRYANT, R; BAILEY, S. L. (1997) Third World Political Ecology. New York: Routledge.

CARVALHO, F. C. (2011) Gestão do território, lugar e conflitos socioambientais: o caso da Usina Termelétrica Porto do Itaqui em São Luís, MA. 121 f. Dissertação (Mestrado em Geografia) - Departamento de Geografia, Universidade de Brasília, Brasília. 
CIDADE, L. C. F.; VARGAS, G. M.; JATOBÁ, S. U. (2008) Regime de acumulação e configuração do território no Brasil. Cadernos Metrópole, São Paulo, n. 20, p. 13-35, $2^{\circ}$ semestre. Disponível em: $<$ http://web.observatoriodasmetropoles.net/download/cm_artigos/cm20_14 4.pdf $>$. Acessado em: 3 set. 2011.

CORRÊA, R. L. (1996) Os centros de gestão do território: uma nota. Revista Território, vol. 1, n.1.

DA SILVA, C. A. F. (1993) A dimensão regional na gestão do território: da integração econômica à integração competitiva. Boletim Goiano de Geografia, vol. 13, n.1, p. 45-63.

DIFERENCIAL ENERGIA EMPREENDIMENTOS E PARTICIPAÇÃO LTDA. (2008) Estudo de Impacto Ambiental (EIA). Empreendimento da Usina Termoelétrica Porto do Itaqui (UTE Porto do Itaqui). Fevereiro.

LIMA, R. J. C. (2009) Movimentos sociais, desenvolvimento e capital social: a experiência do Reage São Luís. In: SANT'ANA JÚNIOR, H. A.; PEREIRA, M. J. F.; ALVES, E. J. P.; PEREIRA, C. R. A. (orgs.). Ecos dos conflitos socioambientais: a RESEX de Tauá-Mirim. São Luís: EDUFMA. p. 225-252.

LITTLE, P. E. (2004) A Etnografia dos Conflitos Socioambientais: bases metodológicas e empíricas. Papers do II Encontro da ANPPAS, Idaiatuba SP. $\quad$ p. $1-9 . \quad$ Disponível em: $<$ http://www.anppas.org.br/encontro_anual/encontro2/GT/GT17/gt17_little .pdf $>$. Acessado em: 28 jan. 2010.

MARTÍNEZ-ALIER, J. (2007). O ecologismo dos pobres: conflitos ambientais e linguagens de valoração. São Paulo: Contexto.

NASCIMENTO, D. T.; BURSZTYN, M. A. A. (2010) Análise de conflitos socioambientais: atividades minerárias em comunidades rurais e Áreas de Proteção Ambiental (APA). Desenvolvimento e Meio Ambiente, n. 22, p. 65-82, jul./dez.

NASCIMENTO, E. P. (2001) Os Conflitos na Sociedade Moderna: Uma Introdução Conceitual. In: BURSZTYN, M. (org.). A Dificil Sustentabilidade: Política energética e conflitos ambientais. Rio de Janeiro: Garamond Universitária, p. 85-105.

PEREIRA, E. D. (org.) (2008) Relatório de Pesquisa de Campo: Caracterização Socioambiental do Povoado de Camboa dos Frades. São Luís: Departamento de Geografia, CCH-UFMA. (Mimeo)

PLATIAU, A. F. B. et al. (2005) Uma crise anunciada. In: THEODORO, S. H. (org.) Mediação de conflitos socioambientais. Rio de Janeiro: Garamond Universitária, p. 23-71. 
SILVA, A. C. P. (1997) Gestão do território: o caso da empresa Fleischmann e Royal no noroeste fluminense. Revista Território, ano II, $\mathrm{n}^{\mathrm{o}}$ 3, jul./dez.

SPÓSITO, M. E. B. (1998) A gestão do território e as diferentes escalas da centralidade urbana. Revista Território, ano III, $\mathrm{n}^{\circ} 4$, jan./jun.

ZAGALlO, J. G. C. (org.). (2004) Considerações Preliminares Sobre a Implantação de um Polo Siderúrgico na Ilha de São Luís. São Luís: Novembro. (Mimeo)

ZHOURI, A.; LASCHEFSKI, K. (2010) Desenvolvimento e Conflitos Ambientais: um novo campo de investigação. Belo Horizonte: Editora da UFMG.

Data de submissão 03/11/2012

Data de aprovação: 05/11/2014 